\section{Sustaining Corporation Members}

Alden Electronics, Inc.

Contel Federal Systems

Harris Corporation

Orbital Sciences Corporation

WSI Corporation

\section{Contributing Corporation Members}

Accu-Weather, Inc.

Gillett Weather Data Services

Particle Measuring Systems, Inc.

Weather Services Corporation

Weathernews, Inc.

\section{Corporation Members}

ACT Sigmex B.V.

AG Risk Management

AT\&T Federal Systems

Aanderaa Instruments, Inc.

AeroVironment, Inc.

The Aerospace Corporation

Air Traffic Services, Civil Aeronautics

Administration of the Republic of China

Air Transport Association of America

Air Weather Service Technical Library

Argonne National Laboratory

Armtec Industries, Inc.

Astro-Space Division, General Electric Co.

Atmospheric and Environmental Research

Atmospheric Environment Service

Audichron Company, Pastel Division

Belfort Instrument Company

Boeing Aerospace

Bristol Industrial \& Research Associates Ltd.

Brock University Library

Brookhaven National Laboratory

Brown \& Dureau Aviation

Calspan Corporation

Caribbean Meteorological Institute

Chanute AFB Technical Library

Climatronics Corporation

Colorado State University, Department of Atmospheric Science

Computer Sciences Corporation

Control Data Corporation

Convex Computer Corporation

Creighton University, Atmospheric Science Program

Curtin Institute of Technology

Dartmouth College Library

Deutscher Wetterdienst

Dobbie Instruments (Australia) Pty.Ltd.

ENSR Consulting \& Engineering

Edinburgh University Library

Enterprise Electronics Corporation
Environmental Instruments, Inc.

Ericcson Radio Space Systems

Etablissement d'Etude et des Recherche Meteo.

European Organisation for the Exploitation of Meteorological Satellites (EUMETSAT)

Factory Mutual Engineering Corporation

Fernbank Science Center

Finnish Meteorological Institute

Florida State University, Department of Meteorology

Foundation of River \& Basin Integrated

Communications-FRICS

Freeport International Weather Service

French Meteorological Office

Galson Mesoweather/Div. of Galson Corporation

GEOMET Technologies, Inc.

HANDAR, Inc.

Harvard University

Horizons Technology, Inc.

IBM/Academic Information Systems

ISIS Corporation

ITT Aerospace/Optical Division

Illinois State Water Survey

ImpulsPhysics USA, Inc.

Indian Institute of Tropical Meteorology

Indiana University Library, Serials Department

Information Processing Systems of California, Inc.

Irish Meteorological Service

Kaijo Denki Co., Ltd.

Kavouras/RAM Inc.

Kaysam Worldwide Inc.

Kean College of New Jersey

Korean Meteorological Services

Laboratoire de Meteorologie Dynamique du CNRS

Lawrence Livermore National Laboratory, Atmospheric and Geophysical Sciences Div.

Lightning Location \& Protection Inc.

Lockheed Austin Division

Lockheed Data Plan

Loral Data Systems

Magnavox Electronic Systems Co.

Marta Systems, Inc.

Massachusetts Institute of Technology, Department of Meteorology

Met One, Inc.

Meteoglobe Canada, Inc.

MeteoMedia, Inc.

The Meteorological Research Institute, The MRI Library

Millersville University of Pennsylvania, Department of Earth Sciences

The MITRE Corporation

Mount Isa Mines, Ltd.

Murray \& Trettel, Inc., Consulting Meteorologists

National Agency of Environmental Protection, Roskilde, Denmark 
National Meteorological Library of the United Kingdom

National Severe Storm Laboratory

New England Weather Service

New Zealand Meteorological Service

North American Weather Consultants

Oceanroutes, Inc.

The Ohio State University, Department of Atmospheric

Sciences

OptiMetrics, Inc.

Oregon State University

Pacific Gas \& Electric Co.

Pennsylvania State University, Department of Meteorology

Pennsylvania State University, Pattee Library

Philippine Weather Bureau-PAGASA

Planning Research Corporation

Purdue University

Pyrometer Instrument Company, Inc.

RMS Technologies, Inc.

Radian Corporation

Raytheon Company

The Republic Group

Republic of Korea Air Force, 73rd Weather Group

Republic of Korea, Meteorological Research Institute

Rotronic Instrument Corporation

Royal Netherlands Meteorological Institute

Royal Observatory, Hong Kong

Rutgers University, Douglass-Cook Library

S.C.E.M. Documentation

Saint Louis University, Department of Earth and Atmospheric Sciences

San Jose State University

Science \& Engineering Analysis Corporation (SEACOR)

Service Argos, Inc.

Service Central D'Exploitation Meteorologique

South Dakota School of Mines \& Technology

Space Systems/Loral

Surface Systems, Inc.

Swedish Meteorological and Hydrological Institute, SMHI

Swiss Meteorological Institute

Systems Applications, Inc.

TECNOIDROMETEO

Teledyne Geotech

Texas A\&M University, Meteorology Department

Travelers Insurance Company
UNISYS Corporation

U.S. Army Atmospheric Sciences Laboratory

U.S. Army Cold Regions Research

U.S. Naval Academy Library

Universal Weather and Aviation

Universita di Bologna, Dipartimento di Fisica

Universitat Freiburg, Meteorologisches Institut

Universitat Innsbruck, Institut fur Meteorologie and Geophysik

Universiti Kebangsaan Malaysia, Library

University Corporation for Atmospheric Research, National Center for Atmospheric Research

University of Alabama in Huntsville

University of Arizona, Institute of Atmospheric Physics

University of Chicago, Department of the Geophysical Sciences

University of Copenhagen, Geophysical Institute

University of Illinois, Department of Atmospheric Sciences

University of Melbourne, Department of Meteorology

University of Michigan, Department of Atmospheric and Oceanic Science

University of Nevada

University of North Carolina

University of North Colorado, Library

University of Oklahoma, Department of Meteorology

University of Sheffield Library

University of Washington, Department of Atmospheric Sciences

University of Wisconsin-Madison, Space Science and Engineering Center

VCS Engineering $\mathrm{GmbH}$

VIZ Manufacturing Co.

Valcom, Ltd.

Viking Instrument \& Photo

Weather Bureau Pretoria, South Africa

The Weather Channel

Weather Consultants Inc.

Weather Corporation of America

Woods Hole Oceanographic Institution

WTVT-TV Weather Service

Yale University, Department of Geology and Physics

R.M. Young Company

Zentralanstalt fur Meteorologie und Geodynamik

Zephyr Weather Information Service

Editor's Note: In order to maintain our production schedule, any changes, deletions, or insertions to the corporation members listing must be made two months prior to intended publication date. For more information regarding corporate membership of the American Meteorological Society, please call (617) 227-2425 or write to the American Meteorological Society, 45 Beacon Street, Boston, MA 02108-3693. 


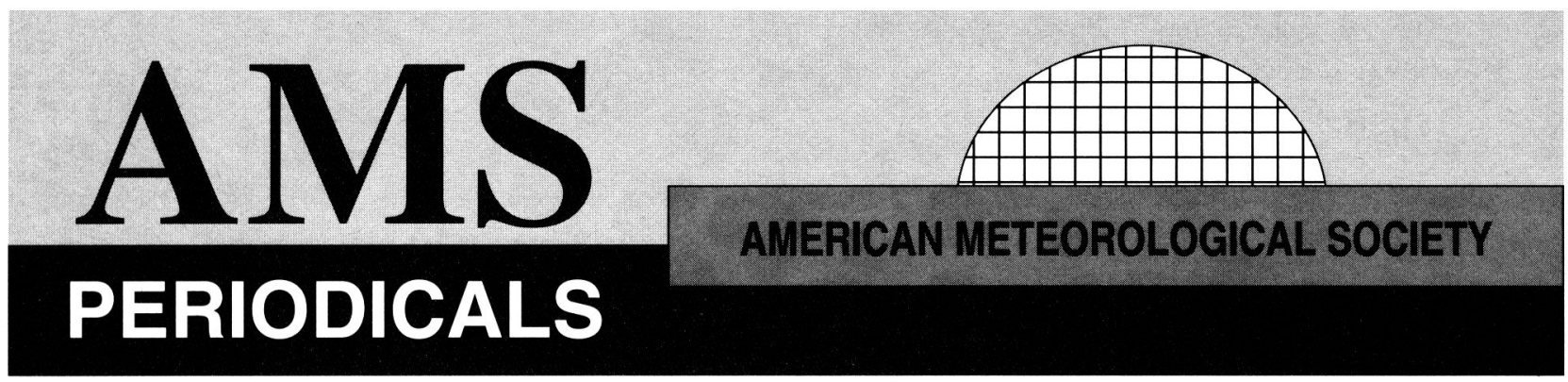

JOURNAL OF THE ATMOSPHERIC SCIENCES (ISSN 0022-4928)

$\$ 320.00$

Vol. 49, 1992. Semi-monthly. Original research papers related to the atmospheres of the earth and other planets with emphasis on the quantitative and deductive aspects of the physics and dynamics of atmospheric processes and phenomena.

JOURNAL OF APPLIED METEOROLOGY (ISSN 0894-8763)

$\$ 165.00$

Vol. 31, 1992. Monthly. Original papers and critical surveys concerned with the applications of the atmospheric sciences to operational and practical goals. Its editorial scope encompasses the full range of applications of meteorology to safety, health, industry, the economy, and general well-being of the human community.

JOURNAL OF PHYSICAL OCEANOGRAPHY (ISSN 022-3670)

Vol. 22, 1992. Monthly. Original research extending our knowledge of ocean physics and the processes acting at its boundaries, including its interaction with the atmosphere and at the sea floor. Papers report observational and theoretical studies of topics such as: ocean and coastal circulation, interpretive regional analyses; ice and water mass formation; eddies, jets and fronts; tides; planetary waves; surface and internal gravity waves; and ocean microstructure.

MONTHLY WEATHER REVIEW (ISSN 0027-0644)

$\$ 205.00$

Vol. 120, 1992. Monthly. Original research and survey papers concerned with weather analysis and forecasting (non-operational); observed and modeled circulations including techniques development and verification studies, and seasonal-annual weather summaries.

JOURNAL OF ATMOSPHERIC AND OCEANIC TECHNOLOGY (ISSN 0739-0572)

$\$ 135.00$

Vol. 9, 1992. Bimonthly. Original research and survey papers related to instrument-system descriptions, exploratory measurement techniques, calibration methods, and performance analyses for the mainstream of atmospheric and oceanic technology, including the development of data-acquisition hardware, real-time and post-analysis software, and signal-processing techniques.

WEATHER AND FORECASTING (ISSN 0882-8156)

Vol. 7, 1992. Quarterly. Original research and survey papers immediately related to the operational forecasting or weather events significant to operational forecast problems including such topics as operational-forecasting techniques, applications of new analysis methods, forecasting-verification studies, and case studies with direct application to forecasting.

JOURNAL OF CLIMATE (ISSN 0894-8755)

Vol. 5, 1992. Monthly. Articles concerned with climate data and analysis, long-term atmospheric variability (seasonal, interannual), climate change and prediction on seasonal and longer time scales, and the impacts of climate change on society.

BULLETIN OF THE AMERICAN METEOROLOGICAL SOCIETY (ISSN 0003-0007)

Vol. 73, 1992. Monthly. The official organ of the Society, devoted to editorials, topical reports to members, articles, professional and membership news, conference announcements, programs, and summaries, book reviews, and Society activities.

METEOROLOGICAL \& GEOASTROPHYSICAL ABSTRACTS (ISSN 0026-1130)

Vol. 43, 1992. Monthly. Abstracts of current world literature in meteorology, climatology, aeronomy, planetary atmospheres, solarterrestrial relations, hydrology, oceanography, glaciology, cosmic rays, and radioastronomy. The abstracts of books, articles, and reprints are arranged by subject categories with extensive cross-referencing. Monthly author, subject, and geographical indexes. Information on the computerized MGA database, 1970-1990, may be obtained by writing to the Society.

METEOROLOGICAL \& GEOASTROPHYSICAL ABSTRACTS (ANNUAL INDEXES)

Vol. 41, Jan.-December 1990. Annually. Cumulative author, subject, and geographic indexes.

Please send prepaid orders to: Publications Department, American Meteorological Society, 45 Beacon Street, Boston, MA 02108-3693. Subscriptions include postage and handling, and are accepted on a calendar-year basis only. There is an additional charge of $\$ 20$ for surface mail outside the U.S. ( $\$ 15$ for Weather and Forecasting and Journal of Atmospheric and Oceanic Technology, $\$ 30$ for Journal of Atmospheric Sciences), and $\$ 90$ for airmail to all countries. The availability and prices of back issues of AMS periodicals will be furnished upon request. (Orders from U.S. and Canada only.) 